Boise State University

ScholarWorks

$8-1-2011$

\title{
Effects of Developmental Conditions on Nestling American Kestrel (Falco Sparverius) Corticosterone Concentrations
}

\author{
Erin H. Strasser \\ Boise State University \\ Julie A. Heath \\ Boise State University
}

\section{(c) $\oplus \Theta \Theta$}




\title{
Effects of Developmental Conditions on Nestling American Kestrel (Falco Sparverius) Corticosterone Concentrations
}

\author{
Erin H. Strasser and Julie A. Heath \\ Boise State University
}

\begin{abstract}
How nestling birds respond to stressful situations may constitute an important survival component that has lasting developmental effects on the hypothalamic pituitary adrenal (HPA) axis. As birds are exposed to increasing amounts of potential anthropogenic stressors through land use change, understanding how these factors contribute to HPA development is important. We examined whether conditions experienced during the nestling stage affected free-living American Kestrel (Falco sparverius) HPA activity prior to fledging. Kestrels experienced varying levels of human disturbance around their nest and we classified this environmental exposure as high or low environmental human disturbance based on traffic patterns and land use. We then exposed some broods from high and low disturbance areas to a standardized disturbance protocol. Prior to fledging we collected blood samples from 25day-old nestlings immediately after capture and 15 min post-capture. Corticosterone (CORT) did not vary with environmental human disturbance levels, disturbance protocol treatment, or with an interaction between environmental human disturbance and disturbance protocol treatment suggesting that nestling kestrels may not perceive external conditions related to human disturbance as stressful or kestrels may acclimate to disturbance. We also compared the relative effects of environmental human disturbance outside the nest cavity, conditions within the nest cavity (brood size), and individual condition (nestling fat scores) on baseline and stress-induced CORT. Baseline CORT did not vary with human disturbance level, brood size or fat score. F at scores best explained stress-induced CORT with nestlings in better condition displaying elevated CORT. These results suggest that individual variation is more likely to explain HPA development compared to nest conditions or the external environment. This study demonstrates the importance of considering the effects of developmental conditions on the stress response at several scales.
\end{abstract}

Keywords: stress, human disturbance, corticosterone, body condition, brood size, American Kestrel

\section{Introduction}

Developmental conditions can have significant effects on adult morphology, behavior, and physiology [26, 4, 28, 10]. U ltimately, conditions experienced during development may impact growth, recruitment, reproduction, or survival that may in turn affect individual fitness and, perhaps, result in population changes $[40,8,27,4,22]$. The hypothalamic-pituitary-adrenal (HPA) axis releases glucocorticoids, particularly corticosterone (CORT), in response to unfavorable or challenging conditions and the HPA may be a system that is sensitive to developmental conditions [43]. An organism's ability to respond to stressful events through secretion of CORT may be both beneficial and costly. Elevated CORT allows individuals to cope with short term or acute challenges by suppressing non-essential behaviors and physiological activities while promoting those required for immediate survival [reviewed in 53, 39]. In nestling birds, elevated CORT may enhance survival by stimulating begging behavior [23], food intake [5, 21] and increased locomotion [12].

Although beneficial during periods of acute stress, chronically elevated CORT (chronic stress) can be detrimental to behavioral and physiological systems [41]. In developing animals chronic stress can have adverse effects that persist through life stages. For example, elevated nestling CORT has been linked to compromised cognitive abilities [21], neophobia [43], changes in baseline CORT or HPA reactivity [34, 13, 22], and reduced survival [4]. At the individual level, nestling condition may be responsible for variation in CORT patterns. CORT plays a role in mobilizing energy during stress through increases in gluconeogenesis, liponeogenesis, and protein catabolism, crucial if food is limited or during energetically expensive periods [39]. Thus the amount of reserves a nestling has 
available can influence the stress response [19]. Nestling HPA activity may also be affected by conditions within the nest such as variation in brood size. As brood size increases, nestlings face competition for food, age or size hierarchies, as well as increased risks of parasite infestation, all of which can influence nestling CORT [37, 38, 24, 22]. Little is known about how larger-scale developmental conditions, and in particular, exposure to the growing levels of human disturbance via land use change and urbanization, affect HPA-axis activity in wild nestling birds.

As human populations expand, understanding the impacts anthropogenic disturbances have on nestling birds will become increasingly important. Human disturbance related to urbanization, scientific investigation, and tourism has been linked to nestling and fledgling baseline and stress-induced CORT levels [31, 50, 33]. These factors may elicit a stress response in young birds as human noise may impair communication between adults and nestlings (e.g. begging vocalizations) [1], or because nestlings may perceive human activity as a p redation threat [2]. As a consequence of long-term exposure to stressors such as human disturbance, nestling competition as a result of large brood size, or variation in body condition, nestlings may display a sensitized stress response (i.e. higher CORT concentrations), which may facilitate coping or lead to repercussions associated with chronically elevated CORT $[13,9]$. A lternatively, nestlings may respond with a down-regulated or dampened stress response [36, 52] presumably to minimize the long-term negative effects elevated CORT has during development [49].

American Kestrels (Falco sparverius) are cavity-nesting raptors that readily utilize nest boxes in human-dominated environments near urban developments, roads, and agricultural areas. B rood size ranges from 3-6 semi-altricial nestlings, which can create competitive social hierarchies with the potential for brood reduction [42]. Kestrels as young as 10 days old respond to acute handling stress and by fledging age ( $\sim 27$ days $)$ are able to mount an adult-like stress response [25]. We investigated whether human disturbance affected American Kestrel HPA-axis activity via a mixed-factor design (i.e., nestlings were "naturally" exposed to different levels of environmental disturbance, such as urban development or road use, and we experimentally treated some nests with a standardized disturbance protocol). We predicted that if human disturbance affects HPA axis development in nestling kestrels then nestlings inhabiting high disturbance areas, or birds exposed to the disturbance protocol, would show elevated baseline and stress-induced CORT patterns. Secondly, we compared whether human disturbance outside the nest cavity, brood conditions within the nest box, or nestling body condition best explained baseline and stress-induced CORT patterns to compare the relative effect of human disturbance to other known HPA effectors.

\section{Materials and Methods}

We monitored 89 nest boxes during the 2008 and 2009 breeding seasons in southwestern Idaho to examine the roles of human disturbance on kestrel HPA-activity. Nest boxes were mounted on posts along secondary roads, on trees or posts in rural and suburban residential areas, and on signs along Interstate 84 . Nest boxes have been posted in these areas for over 20 years to facilitate a long term study of kestrel demography and dispersal [45]. Over time, suburban sprawl has considerably changed land use within the study site, but kestrel occupancy rates remained within the range of 50-65\% [45]. Each year, prior to the breeding season, we cleaned boxes and added new pine shavings. We checked nest boxes weekly from approximately mid-March through mid-August to determine occupancy, clutch initiation, and hatch date. If nestlings were discovered as hatchlings they were aged following Griggs and Steenhof [17]. We banded 10 day old nestlings with USGS aluminum bands. We visited nests again when nestlings were 25 da ys old to collect baseline and stress-induced CORT blood samples (see disturbance protocol below), obtain a final brood count, and score subcutaneous fat scores. We assigned birds a fat score $(0-3)$ based upon the size and shape of fat deposits in the right subalar region. A score of 0 indicated no fat present, 1 represented a trace of fat, 2 indicated a wide streak, and 3 was assigned to fat pads that visibly protruded above the level of the muscle [14]. All procedures were conducted with approval from Boise State University's Institutional Animal Care and Use Committee (protocol \#006-08-007).

\subsection{Environmental Human Disturbance Analysis}

We selected variables related to traffic noise, visual disturbance from passing vehicles, and presence of humans to represent environmental human disturbance [16,32]. At each occupied nest box we recorded the number of lanes and posted roadway speed (mph) and compiled data on average number of vehicles per day from Ada and Canyon County Highway Districts [11] and the Idaho Department of Transportation [20]. If a nest box was at the intersection of more than one road we averaged all values. We selected traffic volume and vehicle speed because traffic noise is best predicted by these two variables and the number of trucks on the road [47]. The proportion of 
human development within a $900 \mathrm{~m}$ radius buffer around the nest box was quantified using Northwest Gap Analysis Program (NWGAP) satellite imagery of southwest Idaho [48]. Human development land cover types consisted of developed open space, developed low, medium and high intensity (reflects presence or absence of structures and roads) and strip or gravel mines. Road, traffic, and human development variables were entered into a principal components analysis (PCA) to create a disturbance index. Some locations may not be independent of one another as some nest boxes were occupied in both 2008 and 2009 or twice in one year. To account for this we removed nest boxes from the PCA if traffic did not vary at those nests between years. The first principal component (PC1) included the variables average number of vehicles per day, posted roadway speed, number of lanes and proportion of human developed area within a $900 \mathrm{~m}$ buffer surrounding the nest. PC1 accounted for $80 \%$ of the total variation among occupied nest boxes and each box was assigned individual PC1 scores to represent environmental human disturbance (Table 1). D isturbance scores ranged from -2.40 to 2.57 with higher PC1 scores indicating higher disturbance areas (i.e. the interstate, busy secondary roads, or highly developed areas) while lower scores indicated lower disturbance areas such as smaller secondary roads with few or no buildings. We classified boxes as low disturbance if they had a PC score of $\leq-0.78$ and high disturbance is the PC score was $>-0.78$ because of a natural break in the distribution of PC scores at -0.78 .

\subsection{Disturbance Protocol}

We used a stratified-random approach to assign nests to a disturbance protocol or control group (no disturbance protocol) to ensure nests from high and low environmental human disturbance areas received treatment and control assignments. The disturbance protocol began when nestlings were approximately 17 days old and ended at 23-24 days old. Control nests were not visited, except for when young were 10 days old, and again when nestlings were 25 days old. We adapted Cyr and Romero's [13] field chronic stress protocol by adding stimuli associated with human disturbance patterns in our study area (residential and agricultural activity). In addition, stimuli were presented to the broods in an unpredictable pattern, a key component of a stressor [36, 13]. Disturbance protocol broods were exposed to a rotation of six stressors that included loud radio placed within the nest box, a novel object placed in or on top of the nest box, a Great-Horned Owl (Bubo virginianus) decoy positioned within view of the nest-box entrance, a human talking, and a human and dog (intermittently barking) near the nest box. These stressors were similar to those used by Cyr and Romero [13]. The disturbance protocol consisted of three randomly selected stressors administered for 30 minutes, spaced 30 minutes to one hour apart for seven days. We randomly chose one day out of the seven-day period in which disturbance protocol broods did not receive the protocol.

We followed a standardized capture and restraint stress protocol to assess the affects of disturbance on baseline and stress-induced CORT within $24-48 \mathrm{hrs}$ after completion of the disturbance protocol [54]. From every brood one or two 25-day-old nestlings were bled within four min (mean $=3 \min 15 \mathrm{sec}, \mathrm{SD}=45 \mathrm{sec}$ ) of nest box contact to reflect baseline CORT. For samples collected in $<4 \mathrm{~min}$, there was no relationship between time and baseline nestling CORT $(r=-0.14, P=0.31)$. After baseline sampling, nestlings were placed in a co vered, compartmentalized plastic bucket. We collected stress-induced samples $15 \mathrm{~min}$ after opening the nest box from two (or one if limited by brood size) nestlings. We sampled stress-induced CORT at $15 \mathrm{~min}$ because previous research on juvenile kestrel CORT secretion patterns showed that most birds reached maximum CORT concentrations within 10-20 minutes $[19,25]$. We did not bleed the same birds twice to avoid underestimating CORT levels [15]. If a brood consisted of one nestling, we collected only baseline from this individual. For all samples, $0.1-0.4 \mathrm{ml}$ of blood was collected using a $261 / 2$ gauge needle and syringe via the jugular vein. Samples were stored in heparinized vials, placed on ice and returned to the lab within five hours of sampling.

\subsection{Corticosterone Determination}

Samples were centrifuged at $10,000 \mathrm{rpm}$ for $15 \mathrm{~min}$ to separate the plasma from the cellular fraction. Plasma was extracted and stored in $1.5 \mathrm{ml}$ microcentrifuge tubes at $-80^{\circ} \mathrm{C}$ until analysis. We determined total CORT concentrations by running eight different enzyme-linked immunosorbent assays (ELISA, Cayman Chemicals). Samples were run in duplicate when possible. Briefly, we twice extracted CORT from 10-30 $\mu$ l of plasma with $5 \mathrm{ml}$ diethyl ether. The lipophilic supernatant was poured off and dried under a stream of nitrogen gas in a warm water bath. Extracted samples were reconstituted with $100 \mu \mathrm{l}$ of EIA buffer, vortexed and $50 \mu \mathrm{l}$ aliquots were added to 96-well plates coated with mouse monoclonal antibody. W e added corticosterone-specific acetylcholinesterase tracer and rabbit corticosterone antiserum and then placed plates on an orbital shaker for two hours. Plates were then developed and read at $405 \mathrm{~nm}$ with a Biotek EL800 plate reader. The concentration of CORT was calculated 
by comparing results to a standard curve. Extraction efficiency was determined by analyzing a standard CORT sample. Inter-assay variation was calculated from repeated values of a pooled sample. All values were corrected for assay extraction efficiency (mean $\pm \mathrm{SD}$ ) $83 \pm 7.6 \%$. Inter-assay variation averaged $8.63 \%$ and average intra-assay variation was $2.02 \%$.

\subsection{Statistical Analyses}

\subsubsection{Environmental Human Disturbance and Disturbance Protocol Analysis}

To examine the effects of environmental human disturbance and disturbance protocol treatment on nestling CORT we ran a three factor repeated measures ANOVA with a block for year. Treatment (control or disturbance protocol) and environmental human disturbance (high or low) were between-group factors and bleed time (0-15 min) was a within-subjects factor. Both baseline and stress-induced CORT was log transformed to meet the assumptions of a parametric test. Nests with only one nestling were removed from the disturbance protocol analysis [46, 3]. Data from males and females were combined because there was no difference in baseline or stress-induced CORT between sexes (all P's $>0.05$ ). We compared our P-value to an $\alpha=0.05$.

\subsubsection{Analyses of Environmental Human Disturbance, Brood Size and Nestling Condition}

To evaluate the influences of human disturbance, brood size, and condition in explaining nestling kestrel HPA-axis activity we used generalized estimating equations (GEE). This approach was utilized as GEEs do not require independent observations and can thus be used to analyze clustered and longitudinal data [18] such as when multiple nestlings are measured within a brood, as was our case. We used GEEs with a normal distribution (Proc GENMOD in Sas 9.2) for the response variables log baseline and log stress-induced CORT and specified a repeated statement for brood. We report parameter estimates $(\beta)$ as well as $95 \%$ confidence intervals (CI).

\section{Results}

We sampled 106 nestlings from 42 nest boxes. Baseline CORT $(\mathrm{n}=57)$ ranged from 1,187 - 17,281 $\mathrm{pg} / \mathrm{ml} \mathrm{with} \mathrm{a}$ mean $\pm \mathrm{SD}$ of 5,328 $\pm 3,705 \mathrm{pg} / \mathrm{ml}$ and stress-induced CORT $(\mathrm{n}=49)$ ranged from 4,893-46,698 $\mathrm{pg} / \mathrm{ml}$ with a mean $\pm \mathrm{SD}$ of $17,022 \pm 8,608 \mathrm{pg} / \mathrm{ml}$. Brood size ranged from 1-6 nestlings and averaged $3.9 \pm 1.3$ nestlings per nest. Fat score did not differ with brood size $(\mathrm{P}>0.3)$, nor were there relationships between environmental human disturbance score and brood size or fat score (all $\mathrm{P}>0.2$ ).

PC scores and human disturbance categories reliably represented human activity around nest sites. $\mathrm{H}$ igh environmental human disturbance areas had more vehicles, faster vehicles, more traffic lanes and more human development compared to low environmental human disturbance areas (Table 2).

\subsection{Disturbance Protocol}

Thirty-three nest boxes with 93 nestlings were used in the disturbance protocol study. Nestlings of all environmental human disturbance groups and disturbance protocol treatment groups responded to acute handling stress as indicated by an increase in total CORT from 0- $15 \mathrm{~min}$ (Figure 1). However, nestlings did not display a significant difference in baseline or stress-induced CORT across environmental human disturbance levels $\left(\mathrm{F}_{1,27}=\right.$ 1.97, $\mathrm{P}=0.17)$, disturbance protocol treatment $\left(\mathrm{F}_{1,27}=0.00, \mathrm{P}=0.97\right)$, or the interaction between environmental human disturbance and disturbance protocol treatment $\left(\mathrm{F}_{1,27}=0.00, \mathrm{P}=0.97\right)$ (Figure 1).

\subsection{Environmental Human Disturbance, Brood Size, and Nestling Condition}

Nestling baseline CORT did not differ with environmental human disturbance, brood size, or nestling fat score (Table 3). Fat score best explained variation in nestling stress-induced CORT. Nestlings with higher fat scores had higher stress-induced CORT ( $\beta=0.38,95 \%$ CI: 0.20-0.56, Table 3, Figure 2). 


\section{Discussion}

In this study we investigated the effects of developmental conditions specifically, exposure to human disturbance, brood size, and individual condition on nestling kestrel HPA-axis activity. N estling kestrel baseline and stressinduced CORT did not vary with environmental human disturbance or disturbance protocol treatment. These results suggest that nestling kestrels may not have perceived environmental human disturbance or our disturbance protocol as a threat, or nestlings exposed to the environmental human disturbance, the disturbance protocol, or both may acclimate and not react with a physiological stress response. The disturbance protocol as well as environmental human disturbance might not have been high enough or of a long enough duration to elicit a stress response in nestling kestrels nor did we determine if individual stressors led to acute stress in nestlings. We expected nestlings to respond to the disturbance protocol because kestrel nestlings do not have the ability to escape stressors and similar stressors have been found to elicit a stress response in other cavity nesting birds [13]. Sounds from talking and dog barking easily transmitted to the box and the radio speakers were placed in the nest box. We observed a strong behavioral reaction (rolled on back and exposed talons) to placement of the stressors and nestlings occasionally vocalized during human presence indicating that the disturbance protocol was perceived as dangerous. However we did not systematically observe these behaviors. It is also plausible that nestlings would respond to the disturbance protocol because of indirect effects such as changes in nest visitation or provisioning rates by adults during the disturbance protocol, a trend suggested by Cyr and Romero [13]. Limited qualitative data showed that adults spent time away from the nest when stressors were present and would vocalize and attack the owl decoy. In regards to the level of environmental human disturbance, the relationship between disturbance and CORT may be noticeable only when human disturbance has reached a cer tain threshold. A lthough nest boxes located in presumably high environmental disturbance areas (e.g. along an interstate) were included in our analyses, a significant number of adult kestrels within our nest box population abandoned nests during incubation in high environmental disturbance areas [44]. Thus, birds in the high environmental human disturbance group, while exposed to more noise, traffic, and human activity compared to birds in our low environmental human disturbance group, may have been surrounded by tolerable human disturbance levels because nests in the highest human disturbance category had already failed.

Our results are similar to several studies suggesting that young birds habituate to human disturbance. For example, fledgling Magellanic Penguins (Spheniscus magellanicus) showed no difference in baseline or stress-induced CORT across tourist and non-tourist visited areas [51] and Black-legged Kittiwake chicks (Rissa tridactyla) did not differ in their baseline or stress-induced CORT across levels of investigator disturbance [7]. R epeated exposure to stressors may have severe negative consequences on developing young such as suppression of growth [29] and reduced cognition [21] and even influence the probability of survival [4]. Thus the ability to maintain low baseline and stress-induced CORT in the face of environmental perturbations may act to minimize the deleterious effects of CORT on developing kestrels.

Although we saw no change in nestling CORT, the consequences of human disturbance could become evident at a later kestrel life stages, as documented in hoatzins (Opisthocomus hoazin). Nestling hoatzin stress response did not differ between undisturbed and tourist exposed nests, but juveniles raised in tourist-exposed sites were sensitized to human presence [31]. It should be noted that interspecific differences in hoatzin and kestrel nest structures, open stick vs. cavity, respectively, might affect exposure to environmental stressors.

As cavity nesters, kestrel nestlings may be buffered from external conditions. Consequently kestrel HPA-axis development and activity may be better explained by conditions within the nest, such as brood size. Although a number of studies have demonstrated the importance of brood size in determining nestling CORT [38, 22] others have implied otherwise [30,35] as was the case in our study; nestling kestrel baseline and stress-induced CORT did not vary with brood size. Food may not be a limiting factor for nestling kestrels in our study or area and thus nestlings may not display pronounced social or developmental hierarchies. Brood reduction can be adaptive by matching a broods' nutritional needs to food abundance and nestling hierarchies in size or strength may lead to brood reduction, often by means of mortality of the weakest offspring. We documented few ( 8 out of 42 nests) cases of brood reduction. We were unable to determine the causes of nestling mortality at these nests. Further, nestling condition (fat score) did not vary significantly with brood size, suggesting that variation in nestling condition is not a factor of food limitation because of larger broods. 
NOTICE: This is the author's version of a work accepted for publication by Elsevier. Changes resulting from the publishing process, including peer review, editing, corrections, structural formatting and other quality control mechanisms, may not be reflected in this document. Changes may have been made to this work since it was submitted for publication. The definitive version has been published in General and Comparative Endocrinology, Volume 173, Issue 1, 2011. DOI: 10.1016/j.ygcen.2011.05.010

Variation in body condition best explained nestling stress-induced CORT patterns. Nestlings with higher fat scores had significantly elevated stress-induced CORT. Baseline CORT was consistent across condition. Heath and Dufty [19] did not detect differences in baseline or maximum CORT across juvenile kestrels of varying body condition. However kestrels in better condition reached maximum CORT levels faster compared to kestrels in poorer condition. If kestrels in this study displayed similar temporal patterns, poorer condition kestrels may have a slower rate of increase in stress-induced CORT concentrations compared to kestrels in relatively better condition. Thus within a time-standardized sampling scheme, it may appear that birds in better condition have elevated stressinduced CORT compared with low fat score nestlings.

There may also be differences in HPA-axis patterns which require alternative assessments of stress. Corticosteroidbinding globulin (CBG) can regulate the amount of free CORT (i.e. unbound CORT) available for uptake into tissues [41] and hence may modulate the stress response. Our study was restricted to total CORT which does not account for variation in free CORT and CBG, both of which respond differently to stressors [6]. For example, although unstressed and chronically stressed European Starling (Sturnus vulgaris) chicks did not differ in their baseline or stress-induced total CORT, stressed nestlings had higher stress-induced free CORT [13]. In Eurasian Kestrels (Falco tinnunculus) older nestlings displayed elevated total CORT and CBG in response to handling but there was no difference in free CORT between age groups [30]. Thus future research should address nestling kestrel CBG levels or free CORT better understand how nestling kestrels respond to potential stressors.

In summary, nestling kestrel CORT patterns are best explained at the level of the individual bird. Nestlings with higher fat scores had elevated stress-induced CORT, but baseline was similar across condition. Neither baseline nor stress-induced CORT varied with environmental or experimental human disturbance or with conditions in the nest, specifically brood size. If nestlings habituate to human disturbance, this could indicate that kestrels avoid the negative consequences elevated CORT has on developing young. However it remains to be known if there are long term effects from exposure to human disturbance or if elevated levels of stress-induced CORT in better condition nestlings is adaptive or not. This study demonstrates the importance of considering the influences of developmental factors at a number of scales.

\section{Acknowledgements}

This project was supported by Boise State University, the Raptor Research Center, North American Bluebird Society, the Society for Integrative and Comparative Biology, and the NSF Idaho EPSCoR Program (EPS-0814387). We appreciate the land owners that allow us to access kestrel boxes on their property. We thank C. Hayes, A. Webber, D. Owen and T. Patel for help in the field. Finally, we thank two anonymous reviewers for thoughtful comments that improved an earlier draft of the manuscript. 


\section{References}

[1] J. R. Barber, K.R. Crooks, K.M. Fristrup, The costs of chronic noise exposure for terrestrial organisms, Trends. Ecol. Evol. 25 (2010) 180-189.

[2] C. M. Beale, P. Monaghan, Human disturbance: people as predation-free predators? J. Appl. Ecol. 41 (2004) $335-343$.

[3] J. Blas, R. Baos, G.R. Bortolotti, T.A. Marchant, F. Hiraldo, A multi-tier approach to identifying environmental stress in altricial nestling birds, Funct. Ecol. 19 (2005) 315-322.

[4] J. Blas, G.R. Bortolotti, J.L. Tella, R. Baos, T.A. Marchant, Stress response during development predicts fitness in a wild, long lived vertebrate, Proc. Natl. Acad. Sci. U.S.A.104 (2007) 8880-8884.

[5] M.M. Bray, Effect of Acth and glucocorticoids on lipid-metabolism in the Japanese-Quail, Coturnix-CoturnixJaponica, Comp. Biochem. Physiol. Part A: Mol. Integr. Physiol. 105 (1993) 689-696.

[6] C.W. Breuner, M. Orchinik, Plasma binding proteins as mediators of corticosteroid action in vertebrates, J. Endocrinol. 175 (2002) 99-112.

[7] J.H. Brewer, K.M. O'Reilly, C.L. Buck, Effect of investigator disturbance on corticosterone concentrations of Black-legged Kittiwake chicks, J. Field Ornithol. 79 (2008) 391-398.

[8] G.P. Burness, G.B. McClelland, S.L. Wardrop, P.W. Hochachka, Effect of brood size manipulation on offspring physiology: An experiment with passerine birds, J. Exp. Biol. 203 (2000) 3513-3520.

[9] D.S. Busch, L.S. Hayward, Stress in a conservation context: A discussion of glucocorticoid actions and how levels change with conservation-relevant variables, Biol. Conserv. 142 (2009) 2844-2853.

[10] M.W. Butler, L.L. Leppert, A.M. Dufty, Jr., Effects of small increases in corticosterone levels on morphology, immune function, and feather development, Physiol. Biochem. Zool. 83 (2010) 78-86.

[11] Community Planning Association of Southwest Idaho (COMPASS). http://www.compassidaho.org/prodserv/traffic_counts.htm. Last visited: December, 2010.

[12] H. Corbel, R. Groscolas, A role for corticosterone and food restriction in the fledging of nestling white storks, Horm. Behav. 53 (2008) 557-566.

[13] N.E. Cyr, L.M. Romero, Chronic stress in free-living European starlings reduces corticosterone concentrations and reproductive success, Gen. Comp. Endocrinol. 151 (2007) 82-89.

[14] J. P. Delong, J. A. Gessaman, A comparison of noninvasive techniques for estimating total body fat and condition in Sharp-shinned and Coopers hawks, J. Field Ornithol. 72 (2001) 349-364.

[15] A.M. Dufty, Jr., Stress responsiveness in nestlings: a comparison of two sampling techniques, Auk 125 (2008) 225-229.

[16] A. Frid, L. Dill, Human-caused disturbance stimuli as a form of predation risk, Conserv. Ecol. 6 (2002) 11 http://www.ecologyandsociety.org/vol6/iss1/art11/

[17] G.R. Griggs, K. Steenhof, Photographic guide for aging nestling American Kestrels, U.S. Department of the Interior Bureau of Land Management, Boise, ID, 2003.

[18] J. W. Hardin, J. M.Hilbe General estimating equations, Chapman and Hall/CRC, Boca Raton, Fl, 2003.

[19] J. A. Heath, A. M. Dufty Jr., Body condition and the adrenal stress response in captive American Kestrel 
juveniles, Physiol. Zool. 71 (1998) 67-73.

[20] Idaho Transportation Department Highway Data Quest. http://www3.idaho.gov/cgi-bin/webster.cgi. Last visited: December, 2010

[21] A.S. Kitaysky, E. Kitaiskaia, J. Piatt, J.C. Wingfield, Benefits and costs of increased levels of corticosterone in seabird chicks. Horm. Behav. 43 (2003) 140-149.

[22] A.Z. Lendvai, C. Loiseau, G. Sorci, O. Chastel, Early developmental conditions affect stress response in juvenile but not in adult house sparrows (Passer domesticus), Gen. Comp. Endocrinol. 160 (2009) 30-35.

[23] C. Loiseau, G. Sorci, S. Dano, O. Chastel, Effects of experimental increase of corticosterone levels on begging behavior, immunity and parental provisioning rate in house sparrows, Gen. Comp. Endocrinol. 155 (2008) 101-108.

[24] O.P. Love, D.M. Bird, L.J. Shutt, Plasma corticosterone in American Kestrel siblings: effects of age, hatching order, and hatching asynchrony, Horm. Behav. 43 (2003) 480-488.

[25] O.P. Love, D.M. Bird, L.J. Shutt, Corticosterone levels during post-natal development in captive American Kestrels (Falco sparverius), Gen. Comp. Endocrinol. 130 (2003) 135-141.

[26] S. Maccari, M. Darnaudery, S. Morley-Fletcher, A.R. Zuena, C. Cinque, O. Van Reeth, 2003. Prenatal stress and long-term consequences: implications of glucocorticoid hormones, Neurosci. Biobehav. Rev. 27 (2003) $119-127$.

[27] M.R. McClung, P.J. Seddon, M. Massaro, A.N. Setiawan, Nature-based tourism impacts on yellow-eyed penguins Megadyptes antipodes: does unregulated visitor access affect fledging weight and juvenile survival? Biol. Conserv. 119 (2004) 279-285.

[28] P. Monaghan, Early growth conditions, phenotypic development and environmental change, Philosoph Trans. R. Soc. Lond. B. Biol Sci. 363 (2008) 1635-1645.

[29] C. Müller, S. Jenni-Eiermann, L. Jenni, Effects of a short period of elevated circulating corticosterone on postnatal growth in free-living Eurasian kestrels Falco tinnunculus, J. Exp. Biol. 212 (2009) 1405-1412.

[30] C. Müller, S. Jenni-Eiermann, L. Jenni, Development of the adrenocortical response to stress in Eurasian kestrel nestlings: defence ability, age, brood hierarchy, and condition, Gen. Comp. Endocrinol. 168 (2010) 474483.

[31] A. Müllner, K.E. Linsenmair, M. Wikelski, Exposure to ecotourism reduces survival and affects stress response in hoatzin chicks (Opisthocomus hoazin), Biol. Conserv. 118 (2004) 549-558.

[32] K. M. Parris, A. Schneider. Impacts of traffic noise and traffic volume on birds of roadside habitats. Ecol. Soc. 14 (2008) 29, http://www.ecologyandsociety.org/vol14/iss1/art29/

[33] J. Partecke, I. Schwabl, E. Gwinner, Stress and the city: Urbanization and its effects on the stress physiology in European Blackbirds, Ecol. 87 (2006) 1945-1952.

[34] V.V. Pravosudov, A.S. Kitaysky, Effects of nutritional restrictions during post-hatching development on adrenocortical function in western scrub-jays (Aphelocoma californica), Gen. Comp. Endocrinol. 145 (2006) 25-31.

[35] M. A. Rensel, T. E. Wilcoxon, S. J. Schoech, Corticosterone, brood size, and hatch order in free-living Florida scrub-jay (Aphelocoma coerulescens) nestlings, Gen. Comp. Endocrinol. 171 (2011) 197-202.

[36] E.L. Rich, L.M. Romero, Exposure to chronic stress downregulates corticosterone responses to acute stressors, 
Am. J. Physiol. Regul. Integr. Comp. Physiol. 288 (2005) R1628-R1636.

[37] N. Saino, R.P. Ferrari, M. Romano, R. Ambrosini, A.P. Moller, Ectoparasites and reproductive trade-offs in the barn swallow (Hirundo rustica), Oecol. 133 (2002) 139-145.

[38] N. Saino, C. Suffritti, R. Martinelli, D. Rubolini, A.P. Moller, Immune response covaries with corticosterone plasma levels under experimentally stressful conditions in nestling barn swallows (Hirundo rustica), Behav. Ecol. 14 (2003) 318-325.

[39] R.M. Sapolsky, L.M. Romero, A.U. Munck, How do glucocorticoids influence stress responses? Integrating permissive, suppressive, stimulatory, and preparative actions, Endocr. Rev. 21 (2000) 55-89.

[40] J.S. Sedinger, P.L. Flint, M.S. Lindberg, Environmental influence on life-history traits - growth, survival, and fecundity in Black Brant (Branta-Bernicla), Ecol. 76 (1995) 2404-2414.

[41] H.S. Siegel, Physiological stress in birds, Biosci. 30 (1980) 529-534.

[42] J.A. Smallwood, D.M. Bird, American Kestrel (Falco sparverius), The birds of North America online (Ed. by A. Poole). Ithaca: Cornell Lab of Ornithology, (2002). http://bna.birds.cornell.edu/bna.html/species/602doi:10.2173/bna.602

[43] K.A. Spencer, S. Verhulst, Delayed behavioral effects of postnatal exposure to corticosterone in the zebra finch (Taeniopygia guttata), Horm. Behav. 51 (2007) 273-280.

[44] E.H. Strasser, Reproductive failure and the stress response in American Kestrels nesting along a human disturbance gradient, Boise State University Theses and Dissertations Paper 86 (2010), http://scholarworks.boisestate.edu/td/86

[45] K. Steenhof, B.E. Peterson, American kestrel reproduction in southwestern Idaho: annual variation and longterm trends. J. Raptor Res. 43 (2009) 283-290.

[46] E.M. Tarlow, M. Wikelski, D.J. Anderson, Hormonal correlates of siblicide in Galapagos Nazca boobies, Horm. Behav. 40 (2001) 14-20.

[47] US Department of Transportation, Highway Traffic Noise, Report No. HEV-21/8-80 (20M). Federal Highway Administration, Washington D. C. (1980) Last visited: May 2011, http://www.nonoise.org/library/highway/traffic/traffic.htm

[48] US Geological Survey, National Biological Information Infrastructure Gap Analysis Program (GAP) National Land Cover, Version 1. (2010) Last visited: December 2010, http://www.gap.uidaho.edu/landcoverviewer.html

[49] H. Wada, T.P. Hahn, C.W. Breuner, Development of stress reactivity in white-crowned sparrow nestlings: Total corticosterone response increases with age, while free corticosterone response remains low, Gen. Comp. Endocrinol. 150 (2007) 405-413.

[50] B.G. Walker, P.D. Boersma, J.C. Wingfield, Field endocrinology and conservation biology, Integr. Comp. Biol. 45 (2005a) 12-18.

[51] B.G. Walker, P.D. Boersma, J.C. Wingfield, Physiological and behavioral differences in Magellanic Penguin chicks in undisturbed and tourist-visited locations of a colony, Conserv. Biol. 19 (2005b) 1571-1577.

[52] B. A. Whitman, C. W. Breuner, A. M. Dufty Jr., The effects of neonatal handling on adrenocortical responsiveness, morphological development, and corticosterone binding globulin in nestling American Kestrels (Falco sparverius), Gen. Comp Endocrinol. (2011) In Press. 
NOTICE: This is the author's version of a work accepted for publication by Elsevier. Changes resulting from the publishing process, including peer review, editing, corrections, structural formatting and other quality control mechanisms, may not be reflected in this document. Changes may have been made to this work since it was submitted for publication. The definitive version has been published in General and Comparative Endocrinology, Volume 173, Issue 1, 2011. DOI: 10.1016/j.ygcen.2011.05.010

[53] J.C. Wingfield, D.L. Maney, C.W. Breuner, J.D. Jacobs, S. Lynn, M. Ramenofsky, R.D. Richardson, Ecological bases of hormone-behavior interactions: The "emergency life history stage", Am. Zool. 38 (1998) 191-206.

[54] J.C. Wingfield, C.M. Vleck, M.C. Moore, Seasonal changes of the adrenocortical response to stress in birds of the Sonoran desert, J. Exp. Zool. 264 (1992) 419-428. 


\section{Figures}

Figure 1: Changes in plasma corticosterone concentrations (mean $\pm \mathrm{SE}$ ) over time between American Kestrel nestlings in nest boxes surrounded by high or low environmental human disturbance and exposed or not to an experimental disturbance protocol. Nestlings did not display a significant difference in baseline or stress-induced CORT across environmental human disturbance levels $\left(\mathrm{F}_{1,27}=1.97, \mathrm{P}=0.17\right)$, experimental disturbance protocol treatments $\left(\mathrm{F}_{1,27}=0.00, \mathrm{P}=0.97\right)$, or the interaction between environmental human disturbance and experimental disturbance protocol treatments $\left(\mathrm{F}_{1,27}=0.00, \mathrm{P}=0.97\right)$.

Figure 2: The relationship between fat score and stress-induced CORT (mean $\pm \mathrm{SE}$ ) of free-living 25-day-old nestling American Kestrels in southwestern Idaho. Birds with more fat in the subalar region tended to have higher stress-induced CORT concentrations 15 min post capture. Numbers beside symbols indicate sample sizes. 


\begin{tabular}{llll}
\hline Principal component & Eigenvalue & $\begin{array}{l}\text { Proportion of } \\
\text { variability }\end{array}$ & $\begin{array}{l}\text { Cumulative proportion of } \\
\text { variability }\end{array}$ \\
\hline PC1 & 3.21 & 0.80 & 0.80 \\
PC2 & 0.65 & 0.16 & 0.96 \\
\hline
\end{tabular}

Table 1: Eigenvalues and eigenvectors for principal components created from the variables average daily traffic volume, posted roadway speed (mph), number of lanes and proportion of human developed land cover in a breeding territory. 


\begin{tabular}{|c|c|c|c|c|c|c|c|c|c|c|}
\hline \multirow[b]{3}{*}{ Variable } & \multicolumn{5}{|c|}{ Baseline CORT } & \multicolumn{5}{|c|}{ Stress Induced CORT } \\
\hline & \multicolumn{3}{|c|}{$95 \% \mathrm{CI}$} & \multirow[b]{2}{*}{$x^{2}$} & \multirow[b]{2}{*}{$\mathrm{P}$} & \multirow[b]{2}{*}{$\beta$} & \multicolumn{2}{|c|}{$95 \% \mathrm{CI}$} & \multirow[b]{2}{*}{$x^{2}$} & \multirow[b]{2}{*}{$P$} \\
\hline & $\beta$ & lower & upper & & & & lower & upper & & \\
\hline Brood size $^{\mathrm{a}}$ & 0.13 & -0.08 & 0.34 & 1.27 & 0.259 & 0.09 & -0.77 & 0.25 & 0.77 & 0.379 \\
\hline Disturbance $^{b}$ & -0.01 & -0.09 & 0.07 & 0.02 & 0.877 & 0.00 & -0.06 & 0.06 & 0.01 & 0.939 \\
\hline Condition $^{\mathrm{c}}$ & 0.08 & -0.11 & 0.27 & 0.43 & 0.511 & 0.38 & 0.20 & 0.56 & 7.62 & 0.006 \\
\hline
\end{tabular}

${ }^{\text {a }}$ Brood size $=$ number of nestlings in a brood at fledging

${ }^{\mathrm{b}}$ Disturbance $=$ disturbance PCA score generated from variables \# lanes, avg. daily traffic, speed (mph), and \% developed land cover within $900 \mathrm{~m}$ buffer around nest.

${ }^{\mathrm{c}}$ Condition= nestling subcutaneous fat score (0-3) as an index of body condition

Table 2: Variables used to explain nestling baseline and stress induced total corticosterone. Effect size ( $\beta$ ), upper and lower $95 \%$ confidence intervals, chi-square and p-values are shown. Bolded values indicate significance at $\mathrm{P}<0.05$. 


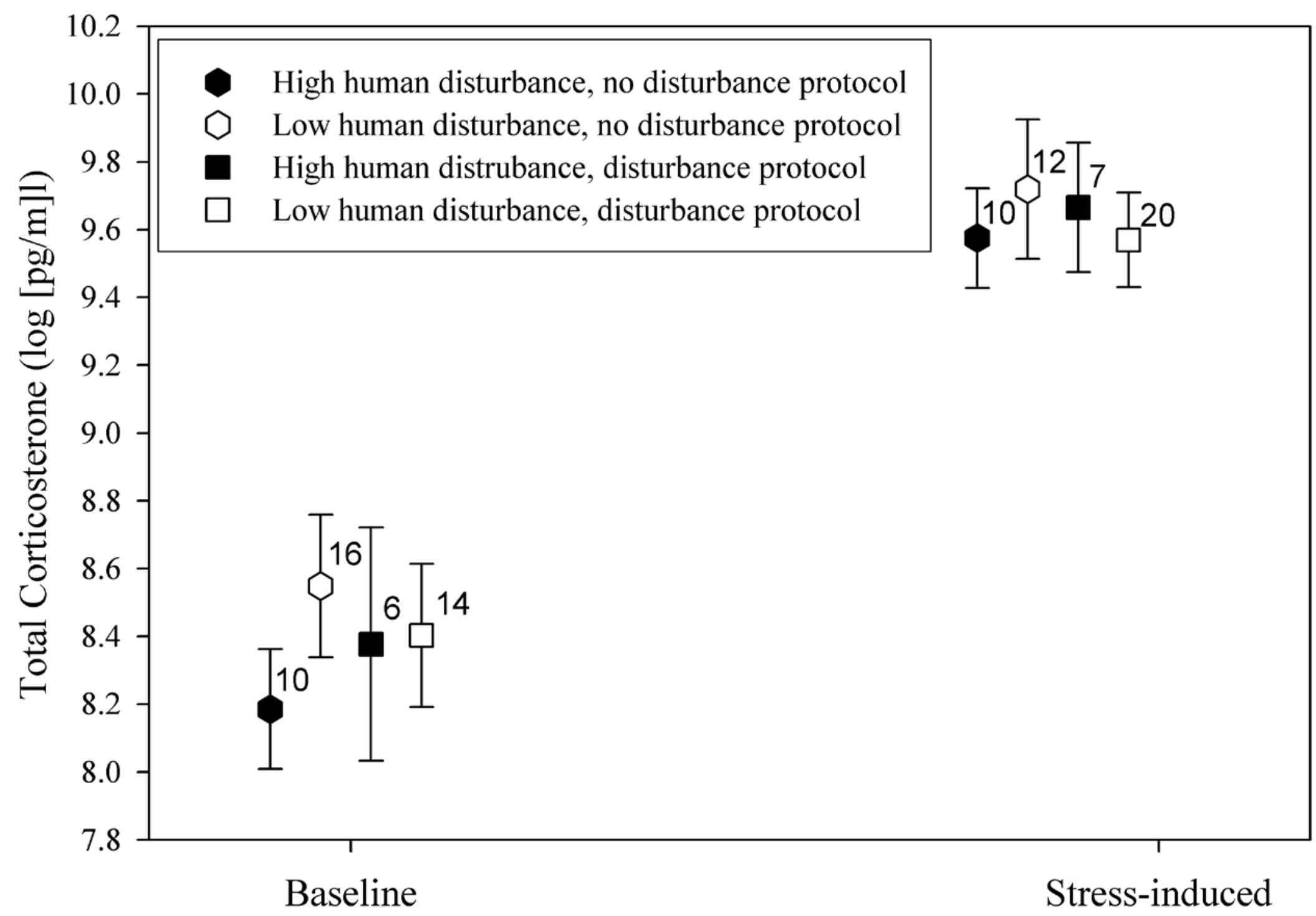

Sampling Period 


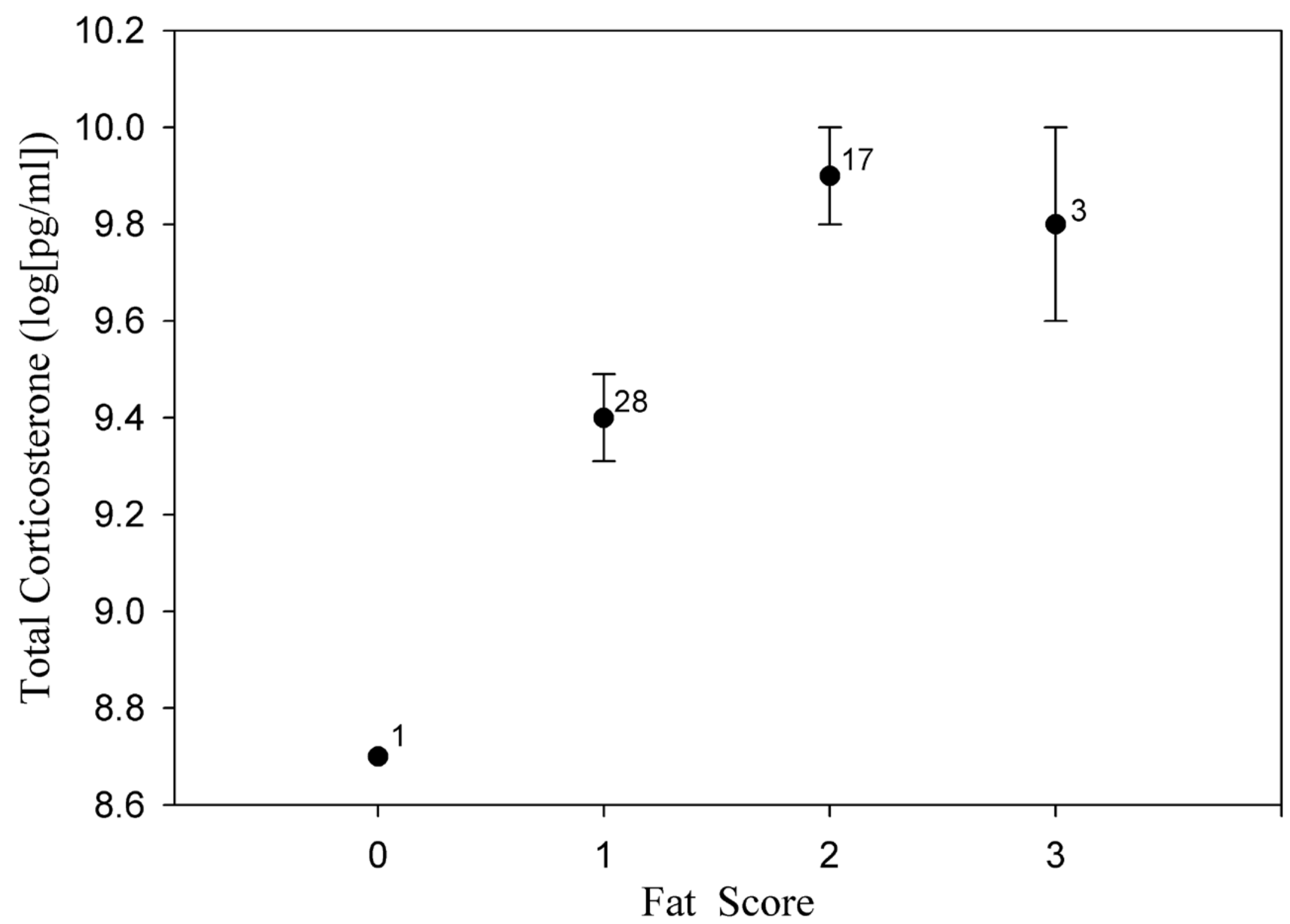

